\title{
O COMPLEXO DA EDUCACÃO EM LUKÁCS: UMA ANÁLISE À LUZ DAS CATEGORIAS TRABALHO E REPRODUÇÃO SOCIAL
}

\author{
Marteana Ferreira de Lima* \\ Susana Vasconcelos Jimenez *
}

RESUMO: O artigo discute a educação em Lukács, a partir de sua Ontologia do Ser Social. Prioritariamente, destaca os elementos que assinalam o lugar da educação no processo de reprodução social, em cuja dinâmica esta manteria, com o trabalho, uma relação de dependência ontológica e autonomia relativa. Explicita que, se, em sentido lato, a educação é um complexo universal, empenhado em efetivar a apropriação, por parte dos indivíduos, das objetivações constituintes do gênero humano, esta não paira sobre a totalidade social, vinculando-se, em sentido estrito, às necessidades da sociedade de classe. Por esse prisma, a análise lukacsiana permite concluir que o complexo da educação, conquanto impelido a manter o sistema de acumulação privada e a exploração do homem pelo homem sob o capital, pode constituir-se em espaço para objetivação de posições teleológicas voltadas à emancipação humana.

Palavras-chave: Lukács; Educação; Reprodução Social.

\section{THE COMPLEX OF EDUCATION IN LUKÁCS:}

AN ANALYSIS BASED UPON THE CATEGORIES OF LABOR AND SOCIAL REPRODUCTION

ABSTRACT: The study discusses the education complex in the context of Lukács' Ontology of the Social Being. First and foremost, it indicates the place of education in the social reproduction process, in whose dynamics, such complex maintains with labor, an ontological dependency and a relative autonomy kind of rapport. It points out that, if, in a lato sense, education represents a universal complex, committed to guarantee that the objectivities which constitute the human gender are appropriated by each individual, it does not hover above social totality, indeed, connecting itself, in a strict sense, to the needs of a class society. From this perspective, Lukacsian analysis allows for the conclusion that, although pushed towards the reproduction of private accumulation and man by man exploitation under the capital system, education may also represent a field for the activation of teleological positions aiming the human emancipation.

Keywords: Lukács; Education; Social Reproduction.

*Doutoranda em Educação Brasileira pela Universidade Federal do Ceará (UFC); Professora da Universidade Regional do Cariri (URCA). Pesquisadora do Instituto de Estudos e Pesquisas do Movimento Operário da Universidade Estadual do Ceará IMO/UECE. E-mail: marteanafl@yahoo.com.br

* *Pós-Doutora em Educação pela Universidade Estadual de Campinas (UNICAMP); Professora da Universidade Estadual do Ceará (UECE); Professora Colaboradora do Programa de Pós-Graduação em Educação da Universidade Federal do Ceará (UFC); Diretora do Instituto de Estudos e Pesquisas do Movimento Operário (IMO/UECE). E-mail: susana_jimenez@uol.com.br 


\section{INTRODUÇ̃̃̃o}

Este artigo apresenta uma análise do complexo da educação em Lukács, à luz das categorias trabalho e reprodução social, delineadas no volume dois da sua Ontologia ${ }^{1}$. Como o complexo da educação não se constitui um objeto sistematicamente examinado por Lukács, o estudo foi desenvolvido a partir de duas linhas de análise: uma atrelada aos enunciados do autor explicitamente vinculados à educação; e a outra voltada à apreensão dos elementos implicitamente vinculados a esse complexo, evidenciados por seus nexos com os demais complexos sociais. Para chegarmos à compreensão da educação, apresentamos algumas reflexões referentes à categoria trabalho, apanhando os lineamentos que compõem a trama relacional entre trabalho e educação. Em relação à reprodução social, destacamos os complexos da linguagem e do direito, examinados por Lukács, e, partindo da sua explicitação, passamos à análise da educação, expondo sua especificidade social, sua caracterização e seu papel para a reprodução social.

\section{TRABALHO E CONSTITUIÇÃO DOS COMPLEXOS SOCIAIS}

Lukács, analisando os elementos ontológicos fundamentais em Marx, compreende o trabalho como fundamento do ser social. Isso não significa, todavia, limitar a totalidade social ao trabalho. Para Lukács, o trabalho funda o ser social, sem, contudo, esgotá-lo. Devido à sua capacidade de produzir mais do que é necessário para a reprodução do seu produtor, o trabalho inaugura um processo de complexificação, alargando o horizonte da reprodução humana, criando novas necessidades e ampliando as formas para satisfazê-las. Como consequência dessa complexificação, chama à vida novos e diferenciados complexos sociais, com os quais estabelece relações e forma uma totalidade social, um complexo de complexos, em cujo cerne pode se efetivar.

Conforme a compreensão lukacsiana, "o trabalho, de fato, como categoria desenvolvida do ser social, só pode chegar à sua verdadeira e adequada existência num complexo social que se mova e reproduza processualmente" (LUKÁCS, 1981, p. 135). Se, em alguns momentos da sua Ontologia, o trabalho foi tomado de forma isolada da totalidade social, 
isso se justifica apenas pela abstração necessária para ir além do fenômeno e penetrar a essência do objeto investigado. Somente por meio da abstração foi possível analisar a estrutura interna do trabalho e apanhar seu caráter fundante para a especificidade do ser social. Nesse sentido, iniciar a análise do ser social a partir do trabalho consiste numa opção ontometodológica alicerçada no fato de que, para Lukács, "no trabalho estão gravadas in nuce todas as determinações que, como veremos, constituem a essência de tudo que é novo no ser social. Deste modo, o trabalho pode ser considerado o fenômeno originário, o modelo do ser social" (LUKÁCS, 1981, p. 14, grifos no original).

Entretanto, efetivada a abstração necessária para explicitar a estrutura interna e a peculiaridade do trabalho, no caminho de volta, a análise lukacsiana coloca essa categoria central "na sua justa posição no contexto da totalidade social, na relação recíproca daqueles complexos de cujos efeitos e contra-efeitos esta emerge e tem força". (LUKÁCS, 1981, p. 135).

Nos limites daquilo que Lukács designa como uma investigação introdutória - sua monumental Ontologia -, a análise de cada complexo singular componente da sociedade, compreendida como complexo de complexos, não é seu objetivo. Porém, na análise da reprodução social, o filósofo húngaro apresenta considerações sobre dois importantes complexos sociais, arbitrariamente escolhidos, com o objetivo de "precisar um pouco a esfera dos problemas e o tipo de abordagem do ponto de vista ontológico, para tornar claro o quão diversamente são estruturados estes complexos" (LUKÁCS, 1981, p. 225). Ao examinar dois complexos basicamente opostos entre si, a linguagem e o direito, a intenção do autor consiste em demonstrar como o processo de estruturação dos complexos singulares é diversificado, não apenas pelo caráter desigual do seu desenvolvimento, mas pela especificidade e pelo lugar ocupado nas relações entre os complexos singulares e na totalidade do complexo social. A peculiaridade de cada complexo "requer um estudo particular da sua gênese, do seu funcionamento e, - se for o caso - da perspectiva da sua extinção, para ser verdadeiramente conhecido na sua especificidade ontológica" (LUKÁCS, 1981, p. 225).

A linguagem é o primeiro complexo examinado por Lukács. Trata-se de uma categoria articulada com as posições teleológicas primárias e secundárias, respondendo a necessidades sociais surgidas a partir da 
relação dos homens com a natureza - mediatizada pelo trabalho - e entre si, na divisão do trabalho e na práxis social em geral. A linguagem se relaciona com a intentio recta e atrela-se à necessidade colocada pelo trabalho de refletir o real na consciência dos homens. Ao mesmo tempo, realiza uma importante função em relação às posições teleológicas secundárias, consistindo no instrumento para influenciar outros indivíduos, agindo sobre a consciência humana. Essa dupla função marca significativamente o surgimento e o desenvolvimento do complexo da linguagem, imprimindo-lhe duas direções: de um lado, o impulso à crescente generalização; de outro, a necessária determinação individualizante. Esse desenvolvimento se realiza predominantemente de forma espontânea, o que não significa a desvalorização do papel jogado pelos indivíduos. A referência de Lukács ao significado da tradução da Bíblia para o alemão, feita por Lutero, para a unificação da língua alemã, demonstra como a ação individual pode surtir efeitos importantes para o desenvolvimento da linguagem e das línguas.

Nem sempre, entretanto, a ação individual é consciente dos seus efeitos imediatos e, principalmente, mediatos produzidos na dinâmica da reprodução social. Por isso, na concepção de Lukács (LUKÁCS, 1981, p. 225), o complexo da linguagem é

\footnotetext{
uma estrutura dinâmica, surgida espontaneamente, cuja reprodução é efetuada por todos os homens na sua práxis cotidiana, na maior parte sem o desejar ou saber, e que está presente como médium inevitável da comunicação em todas as atividades interiores e exteriores dos homens.
}

$\mathrm{Na}$ sua profícua análise sobre o complexo da linguagem, encontramos três aspectos de extrema importância para os fins que nos propomos. Em primeiro lugar, o caráter universal da linguagem é demonstrado pelo fato de que ela "não pode deixar de ser órgão e médium da continuidade evolutiva, da conservação e da superação, de cada esfera, de todos os complexos do ser social" (LUKÁCS, 1981, p. 204). A linguagem assume um papel cuja importância e cujo significado para a reprodução do ser social a tornam presente em toda e qualquer forma de sociedade humana.

Em segundo lugar, além do caráter universal, a linguagem tem uma característica particularizadora: é o único complexo social capaz de mediar a relação dos homens com a natureza e dos homens entre si, vinculando-se às duas formas de teleologia. Mesmo o trabalho, categoria uni- 
versal fundante do ser social, "se relaciona, no sentido verdadeiro, somente com a troca orgânica com a natureza" (LUKÁCS, 1981, p. 204).

O terceiro aspecto refere-se ao caráter espontâneo do seu desenvolvimento. Essa espontaneidade significa que a reprodução da linguagem não é determinada pela divisão de classes e não é vinculada ao atendimento de necessidades inerentes a um grupo específico. Sua reprodução é realizada por todos os membros que compõem a sociedade, atendendo necessidades surgidas espontaneamente na vida cotidiana.

O segundo complexo examinado por Lukács, o direito, atende necessidades específicas surgidas em consequência da divisão de classes.

A necessária regulamentação das atividades sociais desempenhadas pelos singulares surge em estágios bastante iniciais do desenvolvimento da sociabilidade humana. Com a divisão do trabalho, torna-se necessário criar formas para garantir que as funções singulares sejam desempenhadas em conformidade com o fim último do trabalho, que permanece sempre único. $\mathrm{Na}$ sociedade primitiva, contudo, a divisão do trabalho não representa uma ruptura em relação aos interesses comuns e isso mantém a integração dos singulares. Mesmo assim, a real possibilidade de que as decisões alternativas dos singulares não correspondam ao modo socialmente necessário à reprodução do grupo faz nascer um tipo de jurisdição voltada à ordenação desses atos. No entanto, no âmbito da sociedade primitiva, conforme Lukács (1981, p. 205-206), "era ainda supérfluo dar vida a uma divisão do trabalho específica para este propósito". Dessa forma, "os chefes das tribos, os caçadores e guerreiros experimentados, etc., os anciãos podiam desdobrar entre si esta função, cujo conteúdo e forma eram predeterminados pela tradição, pela experiência acumulada ao longo do tempo". Depreendem-se dessa passagem dois aspectos importantes para nossa análise: em primeiro lugar, o conteúdo e a forma característicos dessa função de regulação social eram produzidos espontaneamente, fixados e transmitidos socialmente e mantidos por força da tradição; em segundo lugar, a inexistência de um grupo especializado para desempenhar tal função demonstra que a divisão do trabalho ainda não havia realizado uma ruptura no interior da sociedade, inaugurando as classes sociais e, por isso, os indivíduos que assumem essa função a exercem em nome do interesse comum.

Com a divisão da sociedade em classes e, no seu bojo, a emergência dos antagonismos entre elas, impõe-se a necessidade de uma forma 
diferenciada de regulamentação, não produzida espontaneamente, nem pautada apenas nos costumes e tradição. O complexo do direito emerge como resposta a essa necessidade.

Diferentemente da linguagem, o direito não se constitui como um complexo universal: não existe em todas as formas de sociabilidade, nem é requisitado em todos os tipos de relação social. Além disso, seus surgimento e desenvolvimento não ocorrem espontaneamente, mas se vinculam a uma necessidade específica: "o direito, surgido porque existe a sociedade de classes é, por sua essência, necessariamente um direito de classe: um sistema para ordenar a sociedade segundo os interesses e o poder da classe dominante" (LUKÁCS, 1981, p. 208). Nesse sentido, sua função precípua consiste em atender a interesses particulares, restritos a determinados estratos sociais. Nas palavras de Lukács (1981, p. 225), com efeito, o complexo do direito é

um setor especial da atividade humana que pode existir, funcionar, se reproduzir somente se a divisão social do trabalho autoriza um grupo humano especializado a executar o trabalho aqui necessário, a pensar e agir, no interior de tal especialização, com certa consciência.

A análise lukacsiana sobre a linguagem e o direito certamente apresenta outros elementos assaz significativos em relação a esses complexos. No entanto, nos limites do nosso estudo e considerando o objetivo perseguido, abordamos apenas os aspectos que nos parecem essenciais para fundamentar a análise do complexo da educação.

\section{A ESPECIFICIDADE DO COMPLEXO DA EDUCAÇÃO}

A educação é um complexo social fundado pelo trabalho e, como os demais complexos sociais, estabelece com ele uma relação de dependência ontológica e autonomia relativa.

A dependência ontológica está alicerçada no fato de que, para Lukács (1979, p. 87),

o trabalho é antes de mais nada, em termos genéticos, o ponto de partida da humanização do homem, do refinamento das suas faculdades, processo do qual não se deve esquecer o domínio sobre si mesmo. Além do mais, o traba- 
lho se apresenta, por um longo tempo, como o único âmbito desse desenvolvimento; todas as demais formas de atividade do homem, ligadas aos diversos valores, só se podem apresentar como autônomas depois que o trabalho atinge um nível relativamente elevado.

Como categoria fundante do ser social, o trabalho tem a prioridade ontológica em relação às demais categorias e complexos sociais, que só podem ser produzidos no âmbito da sociabilidade já constituída, em cujo cerne a totalidade social expressa o momento predominante. Os complexos sociais só alcançam autonomia num contexto já crescentemente sociabilizado pelo desenvolvimento do trabalho. Mas tal autonomia não pode se configurar de forma absoluta. Ela é sempre relativa, justamente por conta da dependência ontológica que está na base da sua relação com o trabalho. A autonomia estabelecida nesses complexos deriva do fato de que eles, para realizar funções específicas, essencialmente distintas do intercâmbio entre homem e natureza, assumem características particulares que os diferem do trabalho.

Por ser fundada pelo trabalho, a educação estabelece com ele uma relação de identidade da identidade e da não-identidade. A identidade se consubstancia pelo fato de que o trabalho se transforma no modelo de toda a práxis social, inclusive da educação. Assim, como o trabalho, a educação também se caracteriza pela objetivação de posições teleológicas, movimentando séries causais. Portanto, a educação também se realiza pela relação entre teleologia e causalidade. Contudo, é importante observar a compreensão de Lukács (1981, p. 124) segundo a qual a forma originária do trabalho "sofre mudanças substanciais quando a posição teleológica não visa mais exclusivamente a transformar objetos naturais e a utilizar processos naturais, mas induzir outros homens a realizar por si mesmos, determinadas posições deste gênero". Nesse sentido, a não-identidade se consubstancia no fato de que no trabalho são postas teleologias primárias, as quais realizam o intercâmbio entre homem e natureza e tencionam transformar objetos naturais em valores de uso, enquanto na educação as posições teleológicas secundárias visam a influenciar outros indivíduos a realizarem determinadas posições. Justamente essa diferenciação essencial é o alicerce sobre o qual a concepção lukacsiana sobre a educação é erigida. À luz da análise ontológica, a educação não é trabalho, é práxis; e as funções por ela assumidas a vinculam à reprodução social.

Um aspecto importante dessa diferenciação entre trabalho e práxis é assim enfatizado: 
no próprio trabalho a posição das séries causais se refere a objetos e processos que, relativamente ao seu ser-postos, são inteiramente indiferentes em relação ao fim teleológico, ao passo que as posições que têm por objetivo suscitar nos homens determinadas decisões entre alternativas, trabalham sobre um material que por si mesmo, espontaneamente, já é levado a decidir entre as alternativas. (LUKÁCS, 1981, p. 63).

No trabalho, a objetivação da posição de fim se realiza a partir da escolha entre alternativas possíveis, encontradas na causalidade - a qual é indiferente ao fim posto. Nesse caso, o resultado do trabalho pode não corresponder à intenção do seu executor porque, além de não haver identidade entre sujeito e objeto e de não ser possível conhecer todas as determinações do real, ao movimentar as séries causais, o trabalho produz consequências imprevisíveis, vinculadas ao acaso. $\mathrm{Na}$ educação, são postas teleologias secundárias, voltadas a influenciar o comportamento de outros sujeitos, visando à realização de determinadas posições teleológicas. Aqui, a teleologia dirige-se a outro sujeito (ou vários sujeitos), o qual não é indiferente ao processo. A presença da decisão alternativa em ambos os lados da relação é um importante elemento para a compreensão da especificidade da práxis social e, particularmente, da educação. Nesse sentido, o resultado alcançado pode não coincidir com a intenção original porque, além da presença dos fatores citados em relação às posições teleológicas primárias, na objetivação de posições teleológicas secundárias, a alternativa do indivíduo - alvo da teleologia secundária - também pode ser diferente da finalidade posta.

A educação é um complexo essencial para a reprodução do gênero humano, consistindo na mediação entre a individuação e a generalidade. O caráter social a ela inerente também constitui característica especificamente humano-genérica e se traduz num aspecto que distingue o ser social da esfera precedente.

Examinando o ser social em relação à esfera orgânica, observamos analogias entre o homem e o ser biológico vinculadas ao fato de que, em ambas essas esferas do ser, as categorias essenciais da sua forma peculiar de reprodução subsumem as categorias da esfera do ser precedente e tornam-se o momento predominante. Especificamente, em relação aos animais superiores, é possível que essas analogias se estendam à utilização de formas de comunicação entre os singulares da espécie e à existência da divisão do trabalho. Todavia, tais analogias só se mantêm na aparência. 
Essencialmente, descortinam-se quadros completamente distintos: na esfera biológica, os processos reprodutivos são regidos pelas forças naturais, biologicamente determinadas; no ser social, o momento predominante é assumido pelas forças motrizes sociais, produzidas pelos próprios homens, às quais são subsumidos os processos naturais inerentes à ineliminável base biológica.

Em relação à educação, a existência de analogias entre os animais superiores e o ser social também são observadas na concepção lukacsiana. Entretanto:

estas passam a segundo plano quando se percebe que a ajuda prestada pelos animais adultos aos seus filhotes se reduz a fazê-los aprender de uma vez por todas, ao nível da habilidade requerida pela espécie, determinados comportamentos que, pelas suas vidas, permanecerão constantemente indispensáveis. (LUKÁCS, 1981, p. 152)

Entre os animais, a influência dos adultos na adaptação dos filhotes consiste num processo de complementação e atualização de tendências naturais, sempre em consonância com a caracterização da espécie e em conformidade com as determinações do meio, não havendo a mínima possibilidade de ruptura com os padrões naturais de desenvolvimento e reprodução. Trata-se de um processo circunscrito ao âmbito natural, realizado sob os limites dados em cada espécie pelo script geneticamente determinado.

A essência da reprodução do ser social, diferentemente do incessante repor-o-mesmo da esfera orgânica, consiste em produzir o novo. Isso significa que a sociabilidade não é perene, mas produzida pelos homens no seu devir, dado o caráter histórico da essência e do fenômeno, conforme a compreensão lukacsiana sobre a substância social. Na mesma linha defendida por Marx, Lukács postula que, na reprodução do ser social, a substância é um "princípio ontológico da permanência na mudança", na qual "o persistente é entendido como aquilo que continua a se manter, a se explicitar, a se renovar nos complexos reais da realidade" (LUKÁCS, 1979, p. 78). Nessa continuidade histórica, processual, alicerçada na permanência de uma essência também histórica, em cujo cerne se desdobra a complexificação dos complexos sociais, a educação do homem não pode se assemelhar aos processos inaugurados pela adaptação nos animais. A subsunção da base natural realizada pelo ser social é um proces- 
so que perpassa todos os complexos sociais. Assim, embora a base biológica continue ineliminável, o momento predominante na processualidade dos complexos sociais não consiste nas forças motrizes da natureza e, sim, da sociabilidade.

A compreensão de Lukács sobre a relação entre o biológico e o social no complexo da educação é explicitada de forma contundente pela justificativa das suas observações sobre a educação em sentido estrito: "elucidar o erro hoje difundido, segundo o qual seria a peculiaridade biológica que faria o homem se desenvolver mais lentamente como exemplar autônomo da própria espécie" (1981, p. 152). A primeira referência sobre a educação encontrada na Reprodução de Lukács aparece, não por acaso, na explicitação do processo de recuo dos limites naturais e a subsunção das categorias biológicas em complexos como a alimentação e a sexualidade. Assim como nesses dois complexos, também na educação, "os motivos primários da mudança são de caráter social e não biológico” (1981, p. 153). Enquanto categoria social, a educação retroage sobre a constituição biológica do homem. Não é demais lembrar que o recuo dos limites naturais também ocorre no próprio homem e, nesse sentido, consciência, linguagem, autodomínio, enfim, características especificamente humanas - as quais não são dadas com o nascimento, mas produzidas e apropriadas historicamente - são resultado de práxis sociais, como a educação, e não de fatores biológicos - embora a base biológica seja ineliminável. É importante considerar que a própria extensão do desenvolvimento biológico do homem é consequência da humanização, enquanto seu desenvolvimento social é consequência da complexificação da sociedade. Por isso, conforme Lukács (1981, p. 271),

Para a sociedade desenvolvida é necessário acrescentar, além disso, que esta porção de tempo necessário para tornar o homem um adulto em sentido humano-social é muito mais longa do que aquela necessária em sentido biológico; ele, por exemplo, já alcançou há tempo a maturidade sexual quando, do ponto de vista humano-social, é ainda um menino imaturo. A educação, como já dissemos, é um processo puramente social, é um formar e ser-formado em termos puramente sociais.

Como processo puramente social, a educação é imprescindível à apropriação dos elementos sociais que compõem a essência humanogenérica, exigidos dos indivíduos singulares em cada momento concreto do desenvolvimento histórico-social. 
Por isso, afirma Lukács, "se hoje, nos países civilizados, é generalizada a obrigatoriedade escolar e os rapazes ficam fora do trabalho um tempo relativamente longo, também este tempo deixado livre para a educação é um produto do desenvolvimento industrial" (1981, p. 153). O caráter social e concreto da educação na concepção lukacsiana vai, assim, de encontro às teorias que, independentemente das intenções que as movam, obstruem a compreensão da educação, ao traçarem uma linha contínua entre ela e os processos naturais. Como observamos, o que se estabelece é uma ruptura e, portanto, não apenas o surgimento, mas também a caracterização, a reprodução e a constante complexificação da educação são produtos sociais.

Dada a peculiaridade da reprodução do ser social, na educação dos homens, conforme Lukács (1981, p. 152), "a essência consiste em torná-los aptos a reagir adequadamente a eventos e situações imprevisíveis, novas, que apresentar-se-ão mais tarde nas suas vidas". Diferente dos animais, cujo comportamento é biologicamente determinado e praticamente não sofre alterações ao longo da sua vida, o homem tem sua existência efetivada num ambiente social, no qual a constante complexificação faz emergirem novas e diferenciadas necessidades às quais, sob pena de ruína, ele é obrigado a responder. Em consequência disso, "a educação do homem - no sentido mais lato - em verdade não é jamais totalmente concluída" (LUKÁCS, 1981, p. 152). A sociedade, ao mesmo tempo que exige dele sempre novos comportamentos, novas habilidades, novos conhecimentos, cada vez mais complexos, também produz as formas concretas para reproduzi-los. $\mathrm{Na}$ realização dessa função fundamental, a educação se desdobra em formas diferentes, de acordo com a situação concreta na qual se realiza. É por isso que, em determinadas formações sociais, podemos encontrá-la apenas em sentido lato; enquanto em outras formações é possível que, além dessa educação em sentido lato, seja erigida uma prática educacional em sentido estrito. Embora não exista um limite metafísico entre essas duas formas de educação e sim uma mútua influência, é preciso conhecer suas especificidades para compreender devidamente a dinâmica da relação entre elas e delas com a totalidade social e com a formação do homem. 


\subsection{A EDUCAC̣̃̃O EM SENTIDO LATO}

Considerada em sentido lato, a educação guarda significativa similaridade com a linguagem, pois também é um complexo universal, comparecendo em todas as formas de sociedade constituídas pelo homem. A educação é imprescindível em todos os modos de organização social porque sua função consiste em articular o singular ao genérico, reproduzindo no indivíduo as objetivações produzidas ao longo do desenvolvimento do gênero humano e, com isso, possibilitando a continuidade do ser social.

Ao analisarmos a reprodução, constatamos que as características relacionadas à ineliminável base biológica do ser social são fixadas geneticamente e transmitidas aos singulares através do nascimento. No entanto, as características próprias do gênero, fixadas socialmente, não podem ser transmitidas por processos naturais. O surgimento do complexo da educação no ser social está atrelado a essa necessidade fundamental para a continuidade do homem enquanto ser genérico. A educação surge para desempenhar essa função imprescindível: através dela, cada indivíduo singular se apropria das objetivações que constituem os traços da sociabilidade, as características humano-genéricas produzidas pelos próprios homens.

Assim, a educação tem papel fundamental no desenvolvimento do ser social, tanto na filogênese quanto na ontogênese. Em ambas as linhas de desenvolvimento, cabe à educação realizar o "acabamento", mencionado por Lukács como parte do processo do devenir-homem do homem. Esse "acabamento" consiste na produção das características necessárias para atender às "novas e grandes exigências derivadas da sociabilidade, com as quais se defronta quem está se tornando homem (postura ereta, linguagem, capacidade para o trabalho, etc.)" (LUKÁCS, 1979, p. 95).

No desenvolvimento ontogenético, a passagem do indivíduo de membro da espécie a partícipe do gênero humano só é possível por meio da apropriação dos elementos culturais essenciais à humanização do homem. Consciência e linguagem são complexos fundamentais para a efetivação dessa passagem. Entretanto, a educação tem significado bastante expressivo nesse processo, sendo fator determinante à aquisição da linguagem e à elevação da consciência de mera potencialidade - dada com o 
nascimento - à categoria social erigida em órgão e médium da continuidade da substância do ser social. A educação, portanto, se articula com o desenvolvimento dos complexos sociais imprescindíveis para a continuidade do ser social e, dialeticamente, necessita deles para sua efetivação.

Enquanto a linguagem e a consciência consistem nos instrumentos para fixar e transmitir os conhecimentos produzidos, a educação é o processo que realiza sua transmissão e, ao efetivar a apropriação dos elementos constituintes da sociabilidade, também concorre para o recuo dos limites naturais, possibilitando o desenvolvimento das funções especificamente humanas e a subsunção dos aspectos biológicos.

Em relação à filogênese, a educação também comparece como o complexo que realiza a transmissão das objetivações humano-genéricas e contribui para a reprodução social. Especialmente pelo papel realizado na reprodução ontogenética, a qual constitui a base da reprodução filogenética. Isso reforça seu caráter universal.

Embora seja um complexo universal e sua reprodução se realize espontaneamente, a educação não coincide totalmente com a linguagem. Pelo contrário, há diferenças fundamentais. $\mathrm{O}$ aspecto decisivo que distingue educação e linguagem repousa na peculiaridade do complexo da linguagem, na sua capacidade de mediar tanto o intercâmbio entre homem e natureza quanto as relações dos homens entre si. A educação, por sua vez, se articula apenas com a práxis social, com a relação entre os homens. Embora no trabalho seja possível a aprendizagem de habilidades, a aquisição de conhecimentos, o desenvolvimento do autodomínio, etc., tudo isso é fruto da exteriorização, própria do trabalho, e não se vincula à educação. O que significa que o trabalho, em si mesmo, não é educação.

\subsection{A EDUCAC̦ÃO EM SENTIDO ESTRITO}

A análise dos complexos sociais deve se pautar, conforme Lukács (1981, p. 205), por uma ótica histórica, considerando que, frequentemente, "o estágio superior do desenvolvimento histórico-social, que destes marca a estrutura e a dinâmica, se encontra em uma relação diametralmente oposta com as suas origens". O complexo do direito, como vimos, descreve essa trajetória.

A mesma linha de desenvolvimento pode ser percebida em relação ao complexo da educação. Nos seus primórdios, a educação compa- 
rece na totalidade social como um complexo universal e efetiva-se espontaneamente. Surge para atender a necessidade universal de continuidade da substância do gênero humano no processo de reprodução social. Sua função remete, portanto, à transmissão e à apropriação das características que compõem a generidade em cada momento concreto, concorrendo para a constituição do indivíduo como partícipe do gênero. A complexificação do trabalho, entretanto, ao produzir a divisão do trabalho e, especialmente, a divisão de classes, atua sobre o complexo da educação e modifica sua constituição inicial.

Essa influência do trabalho sobre a educação é explicada pela relação de dependência ontológica, à qual já nos referimos. A prioridade ontológica do trabalho faz com que a educação seja um complexo dependente. Tal prioridade se expressa em dois momentos: primeiro, na gênese do ser social, porque o trabalho é sua categoria fundante; depois, na reprodução social, porque "a reprodução biológica da vida forma a base de ser de todas as manifestações vitais; a primeira sem as segundas é possível, o contrário, não" (LUKÁCS, 1981, p. 234).

A dependência ontológica da educação não se traduz, todavia, em ausência de autonomia. Ao contrário, pois os complexos particulares precisam de autonomia para poder realizar suas funções específicas. No entanto, é preciso observar que, na concepção lukacsiana, a autonomia dos complexos é sempre relativa, uma vez que, para Lukács (1981, p. 245), os complexos

apenas no interior da dinâmica concreta do desenvolvimento econômico, a ele reagindo concretamente, executando o quanto tal desenvolvimento requer da sociedade, se opondo - em determinadas condições objetivas e subjetivas - às suas tendências concretas, etc., podem encontrar a sua verdadeira especificidade, podem conquistar uma autêntica autonomia.

As consequências dessa relação podem ser vinculadas a três importantes movimentos do complexo da educação. Em primeiro lugar, vale repetir que é o trabalho que provoca o salto ontológico para a esfera do ser social e, em decorrência da sociabilização por ele inaugurada, funda a educação como complexo social, essencialmente diferente dos processos de adaptação presentes entre os animais.

Em segundo lugar, a complexificação do trabalho, sua divisão e as consequências dela advindas impõem uma complexificação das rela- 
ções sociais e constituem sociedades internamente cada vez mais complexas e heterogêneas. Em consequência disso, a educação, cuja "essência consiste em influenciar os homens a fim de que, frente às novas alternativas da vida, reajam no modo socialmente desejado" (LUKÁCS, 1981, p. 153), também passa por um processo de complexificação.

Embora Lukács não descreva tal processo, a partir da sua análise da reprodução, é possível apresentar, pelo menos em linhas gerais, alguns elementos concretos que contribuem para o delineamento dessa complexificação da educação. Em relação à sociedade primitiva, erigida sobre o trabalho comum, a educação se efetiva de forma espontânea e difusa. A observação lukacsiana sobre o prestígio dos anciãos nessa forma de sociabilidade dever-se a uma vida mais longa, pela possibilidade de um acúmulo maior de experiências empíricas, evidencia o caráter amplo da educação: valores, tradições, conhecimentos, etc. eram transmitidos de forma espontânea, através da práxis social. Com a divisão do trabalho, surge a necessidade de regulamentar os atos individuais e tal processo é realizado, como constatamos, basicamente pelos indivíduos mais experientes do grupo. Em relação à educação, é também assim o início do processo de diferenciação, quando os rituais de passagem, as práticas educacionais mais específicas - vinculadas aos modos do trabalho ou às tradições do grupo - eram assumidas pelos anciãos. Com a crescente complexificação social e a divisão do trabalho em profissões, o conjunto de conhecimentos referentes a cada profissão particular passa a ser transmitido mediante práticas educacionais não mais espontâneas. As transformações na divisão do trabalho, indo da corporação à grande indústria, refletem-se significativamente sobre a educação. Na corporação, "cada trabalhador, ao menos no período do florescimento, devia ser educado a dominar de todos os pontos de vista e perfeitamente o tipo de produção que cabia à sua corporação" (LUKÁCS, 1981, p. 179). Como a cada corporação estão coligados diferentes conhecimentos, relativos ao tipo de produção efetivada, não podemos esperar que a educação em sentido amplo possa alcançar tais resultados. A corporação exige uma educação em sentido estrito, orientada para aquela formação específica. Com a manufatura e a industrialização, as exigências postas para a formação dos indivíduos alargam-se ainda mais e produzem consequências significativas no complexo da educação. A principal delas se traduz no terceiro movimento, que consiste na transformação da educação de um complexo uni- 
versal, espontaneamente reproduzido, em sentido amplo, para a educação em sentido estrito, a qual surge por força da divisão de classes e é influenciada pelos interesses de classe. O surgimento da educação em sentido estrito, todavia, não se traduz na eliminação da educação em sentido lato. Assim como o trabalho concreto, produtor de valores-de-uso, permanece efetivamente presente - mesmo que, em maior ou menor escala, subsumido ao trabalho abstrato - nas sociedades divididas em classes, inclusive no capitalismo, a educação em sentido lato também comparece em todo e qualquer modelo de sociabilidade. A educação em sentido estrito surge como uma diferenciação no interior da educação em sentido lato, mas não a substitui. $\mathrm{O}$ que se estabelece efetivamente é uma relação de mútua influência entre ambas.

A educação em sentido estrito se assemelha ao complexo do direito. Entre outras coisas, isso significa que ela surge para atender interesses particulares e não universais. Em sentido estrito, a educação também comparece como práxis social e teleologia secundária; além disso, mantém sua relação de dependência ontológica e autonomia relativa em relação ao trabalho. A diferença fundamental entre educação em sentido lato e educação em sentido estrito consiste no caráter universal da primeira e na dependência da divisão de classes da segunda. Por outro lado, em sentido lato, a educação é reproduzida espontaneamente e não pressupõe a divisão de classe; já em sentido estrito, sua reprodução é influenciada pelos antagonismos de classe. E, nesse sentido, como afirma Lukács (1981, p. 127), "uma vez surgidas as sociedades classistas, qualquer questão pode ser resolvida em direções diversas: depende do ponto de vista de classe a partir do qual se busca a resposta para o dilema". Por isso, outra diferença essencial entre essas duas formas de educação consiste no fato de que, enquanto a educação em sentido lato se realiza pela síntese de atos singulares de qualquer membro da sociedade, em sentido estrito, a educação é orientada predominantemente por um grupo particular. Basta pensarmos, para nos determos numa forma concreta, nas leis e diretrizes que incidem sobre a educação e são produzidas por um segmento particular, sob a influência da ideologia da classe dominante.

Em consequência da dependência ontológica, o complexo da educação tende a responder às necessidades surgidas no âmbito da reprodução social e, como "toda sociedade reclama dos próprios membros uma dada massa de conhecimentos, habilidades, comportamentos, etc.: 
conteúdo, método, duração, etc. da educação em sentido estrito são consequências das necessidades sociais assim surgidas" (LUKÁCS, 1981, p. 153). Todavia, entre educação em sentido estrito e educação em sentido lato não se pode traçar um limite ideal preciso: são processos que se interpenetram e se influenciam. Nessa perspectiva, a educação em sentido estrito, ao incidir sobre a educação em sentido lato, estende a ela a ideologia dominante que influencia sua prática. Os processos educacionais em sentido lato, cujos desenvolvimento e efetivação contam com a participação de todos os sujeitos que formam a totalidade social e não de um grupo particular (ou vários), reproduzem práticas muitas vezes alicerçadas em interesses contrários àqueles vinculados à educação em sentido estrito. A educação em sentido lato perpassa a educação em sentido estrito e também influencia sua objetivação. Nessa relação de influência mútua, o momento predominante é a totalidade social.

\subsection{EDUCAÇÃO E REPRODUĈ̣̃O SOCIAL}

O complexo da educação, em sentido lato ou estrito, também estabelece uma relação com os outros complexos sociais, os quais podem influenciá-lo ou ser por ele influenciados. Isso significa que, embora o complexo da economia assuma a prioridade ontológica diante da educação, não a determina. A autonomia relativa da educação deixa claro que ela, além de não ser um instrumento a serviço do complexo da economia, pode influenciar essa esfera social. Contudo, sob hipótese alguma a educação pode ser considerada como um complexo que goze de autonomia absoluta. Pelo contrário, a atribuição de uma autonomia absoluta a esse complexo conduz à sua fetichização. Como assinala Lukács (1981, p. 226): "já que também os complexos que surgem e funcionam espontaneamente, quando se tornam objeto da consciência, são 'geridos' por grupos humanos neles especializados, é fácil que os seus interesses façam surgir, no campo cognitivo, tal fetichismo".

Assim, a assunção da educação como um complexo autônomo, autolegal, no qual a dinâmica da totalidade social não exerce influência, pode ser compreendida, à luz da ontologia lukacsiana, como uma forma de fetichização que erige em naturalidade dada a forma de efetivação peculiar de um complexo que atenda aos interesses particulares de determinado segmento social. Uma forma concreta de tal manipulação é per- 
cebida nas teorias que defendem a educação como um campo neutro, no qual as determinações sociais, políticas, econômicas - numa palavra: a totalidade social - não exercem influência sobre seu funcionamento. Num sentido completamente contrário, mas igualmente equivocado, surgem as teorias que postulam uma dependência absoluta da educação em relação à totalidade social.

Concernente à relação entre dependência ontológica e autonomia relativa, Lukács apresenta como tertium datur uma perspectiva dialética, na qual é possível que esses dois opostos interajam na processualidade que imprime a dinâmica do complexo da educação. Numa palavra: a educação não é totalmente determinada pela esfera da economia ou pela totalidade social, mas não paira sobre esta como se estivesse acima dessa dinâmica concreta e desenrolasse uma prática redentora. Como momento predominante, a totalidade social é responsável pela produção das necessidades e das possibilidades relacionadas ao complexo da educação. Os caminhos traçados pela educação, entretanto, representam a síntese dos atos teleológicos singulares concretos. Isso abre uma margem de autonomia para essa prática social, uma vez que os atos singulares sempre se realizam mediante a alternativa e a síntese desses atos não assume, por qualquer hipótese, caráter teleológico.

Como teleologia secundária, a educação visa a influenciar os indivíduos a realizarem determinadas posições teleológicas, traduzidas nos comportamentos desejados em cada sociedade concreta. Assim, a educação representa uma forma de ajuste das decisões individuais às necessidades e aos valores da sociedade. Afirma Lukács (1981, p. 153154), na dinâmica da reprodução social,

este propósito se realiza sempre - em parte - e isto contribui para manter a continuidade na transformação da reprodução do ser social; mas ele a longo prazo fracassa - em parte, - ainda uma vez, como sempre, e isto é o reflexo psíquico não só do fato que tal reprodução se realiza de modo desigual, que ela produz continuamente movimentos novos e contraditórios, aos quais nenhuma educação, por mais prudente, pode preparar suficientemente, mas também do fato que nestes momentos novos se exprime - de maneira desigual e contraditória - o progresso objetivo do ser social no curso de sua reprodução.

A essência da educação - influenciar os homens para que reajam no modo socialmente desejado -, à medida que se realiza, contribui para 
a continuidade do ser social, mediando a relação entre os sujeitos singulares e o gênero. Entretanto, com a complexificação do trabalho e da sociabilidade, as relações sociais se tornam mais complexas e impulsionam a elevação das individualidades a patamares cada vez mais altos. Nesse desenvolvimento contraditório e desigual, por mais prudente, nenhuma educação é capaz de preparar suficientemente os indivíduos. Mesmo quando realiza sua função essencial, isso não significa que ela possa determinar completamente o comportamento dos indivíduos.

Esse "fracasso" da educação deve-se, além do desenvolvimento contraditório e desigual do ser social, também, a outros fatores importantes. A posição teleológica impulsiona cadeias causais mais numerosas e diversas do que pretendia e a síntese dessas posições é mais do que a sua simples justaposição. $\mathrm{Na}$ educação, as posições teleológicas secundárias também põem em movimento séries causais não previstas, não intencionadas, como resultado do caráter próprio da práxis humana, a qual - por ter uma estrutura semelhante à do trabalho, também como este - produz mais do que almejava. A síntese das posições teleológicas secundárias ou até mesmo determinada posição, no âmbito da práxis educacional, pode produzir resultados bem diferentes, ou mesmo contrários, daqueles postos como finalidade. Entretanto, "estes em sentido ontológico são resultados da educação assim como o são aqueles nos quais o educador vê realizadas as finalidades adequadas" (LUKÁCS, 1981, p. 272).

Os efeitos da educação sobre o indivíduo não se traduzem como um processo de ajustamento puro e simples à sociedade porque "toda intervenção sobre o homem (mesmo sobre a criança) suscita nele decisões alternativas, de maneira que o seu efeito pode muito bem ser, e muito frequentemente o é, o contrário do desejado" (LUKÁCS, 1981, p. 327). Ao se apropriar das objetivações humano-genéricas, à medida que realiza sua individuação, o homem também se constitui como membro do gênero e contribui para sua reprodução. Todo esse processo se edifica sobre a objetivação de posições teleológicas alicerçadas na alternativa. Uma vez que o comportamento do homem é ativo e na alternativa encontra-se a liberdade como possibilidade, "ele não acolhe simplesmente o mundo circundante e as suas mudanças se adaptando a eles, mas reage ativamente, contrapõe às transformações do mundo externo uma práxis peculiar dele” (LUKÁCS, 1981, p. 180). É justamente por isso que o homem não é determinado pela sociedade, mas integra com ela, nela, 
uma relação complexa na qual se dá uma influência mútua - embora o peso de cada um desses polos na relação varie em cada caso concreto. Isso é correto tanto quando os resultados da educação correspondem às intenções originais, quanto quando seguem rotas completamente divergentes daquelas postas.

Para Lukács, afirmar que o homem dá respostas é reiterar a assertiva marxiana segundo a qual "os homens fazem a própria história, mas não a fazem de modo arbitrário, em circunstâncias escolhidas por eles mesmos, mas nas circunstâncias que eles encontram diretamente diante de si, determinadas pelos fatos e pela tradição" (MARX in LUKÁCS, 1981, p. 262-263). Aqui, se expressa com toda a clareza possível a dialética que preside a relação entre indivíduo e totalidade social. As circunstâncias não são escolhidas pelos homens porque correspondem, em cada momento e em cada situação, à síntese não-teleológica dos atos singulares teleologicamente postos. No entanto, afirmar que o homem é resultado da sua própria práxis significa que cada uma das suas respostas tem sempre caráter alternativo; e, ao mesmo tempo, elas retroagem sobre o seu produtor, uma vez que cada resposta singular é ligada por muitos liames à síntese social e à continuidade histórica do gênero humano.

\section{CONSIDERAC̣̃̃ES FINAIS}

A função precípua da educação consiste em efetivar a apropriação das objetivações constituintes do gênero humano. Ao contrário das características biológicas, cuja transmissão se realiza por processos naturais, via hereditariedade, as características próprias do gênero humano precisam ser apropriadas por cada indivíduo singular. Através da apropriação dessas características e da realização de posições teleológicas concretas, os singulares constituem-se como partícipes do gênero, ao mesmo tempo em que produzem a sua individualidade. $\mathrm{Na}$ compreensão lukacsiana, a educação é um complexo social fundamental para a realização desse processo, o que a torna indispensável em todas as formas sociais concretas. Em sentido lato, ela se constitui como um complexo universal; em sentido estrito, sua origem vincula-se a necessidades particulares, oriundas da sociedade de classes. Entre essas duas formas de educação, não há uma separação metafísica e, sim, influência mútua. 
Em sentido amplo, a educação se assemelha à linguagem pelo caráter universal e pela espontaneidade do seu desenvolvimento. Mas se distingue da linguagem pelo fato de só comparecer na relação dos sujeitos entre si, na práxis social, enquanto a linguagem se articula com a práxis e com o trabalho.

Em sentido estrito, assemelha-se ao complexo do direito e surge como consequência da complexificação do trabalho e da divisão de classes. Como é influenciada por interesses de classes, os grupos que a manipulam podem apresentá-la como um complexo que tem autonomia absoluta, como forma de fetichizar sua função e articulá-la com a reprodução do status quo.

À luz da ontologia lukacsiana, a compreensão da educação como panaceia geral desconsideraria a relação de dependência ontológica que esse complexo mantém com o trabalho, na sua gênese, e com a esfera da economia, na sua reprodução. Pelo fato de a educação manter uma dependência ontológica em relação à economia, sua efetivação, seja em sentido lato ou estrito, não pode pairar sobre a totalidade social e ser erigida em mecanismo de ajuste e correção das mazelas sociais.

Por outro lado, gozando de autonomia relativa, não é deterministicamente ordenada pela sociedade. Assim, o campo específico da sua realização pode ser o espaço para a objetivação de posições teleológicas concretas vinculadas à emancipação humana ou destinadas a manter as desigualdades sociais e a exploração do homem pelo homem. Em ambos os casos, o material sobre o qual opera essas teleologias secundárias é um sujeito que também reage com alternativas, podendo produzir resultados bem diferentes daqueles intencionados pelas práticas educacionais. 


\section{REFERÊNCIAS}

LUKÁCS, G. In:HOLZ, H.H; KOFLER,L.; ABENDROTH,W. Conversando com Lukács. Rio de Janeiro: Paz e Terra, 1969.

LUKÁCS, G. As bases ontológicas do pensamento e da atividade do homem. Temas de Ciências Humanas. São Paulo: Ciências Humanas, 1978.

LUKÁCS, G. Ontologia do ser social: os princípios ontológicos fundamentais de Marx. São Paulo: Ciências Humanas, 1979.

LUKÁCS, G. Per una Ontologia dell’Essere Sociale. Roma: Riuniti, 1981. v. 2.

\section{NOTA}

1 Ainda não há uma publicação em português que contemple toda a Ontologia de Lukács. Temos apenas dois capítulos da primeira parte: "A falsa e a verdadeira ontologia de Hegel" e "Os princípios ontológicos fundamentais de Marx", publicados pela editora Ciências Humanas, como livros separados, ambos traduzidos por Carlos Nelson Coutinho. A obra completa foi publicada em italiano, sob o título Per una ontologia dell'essere sociale, e dividida em três volumes. As categorias trabalho e reprodução são analisadas pelo filósofo húngaro no volume dois.

Recebido: $19 / 03 / 2010$

Contato:

Universidade Estadual do Ceará Instituto de Estudos e Pesquisas do Movimento Operário Imo Avenida Paranjana, 1700 Itaperi

CEP 60740-000 Fortaleza, CE Brasil 